\title{
Perlindungan Hukum Terhadap Perubahan Data Fakir Miskin Peserta Penerima Bantuan Iuran Yang Dinonaktifkan Menjadi Peserta Non Penerima Bantuan Iuran (Studi Dinas Sosial Kota Medan)
}

\author{
Apri Amalia ${ }^{1}$, Sahbudi $^{2}$ dan Ivan Duna Husada ${ }^{3}$ \\ 1,2,3Program Studi Ilmu Hukum, STIH Asy-Syafiiyah Medan \\ Corresponding author. Email : apriamalia03@gmail.com
}

Naskah diterima: 18-11-2020 revisi: 05-01-2021; disetujui: 18-05-2021 DOI: https://doi.org/10.46257/jrh.v25i1.162

\begin{abstract}
Abstrak
Kementerian sosial mengeluarkan Surat Keputusan (SK) Menteri Sosial Nomor 79 Tahun 2019 tahap keenam, per 1 Agustus 2019. Kementerian Sosial telah menonaktifkan sebanyak 5.227 .852 juta peserta Badan Penyelenggara Jaminan Sosial (BPJS) Kesehatan Penerima Bantuan Iuran (PBI). Alasannya adalah defisit anggaran APBN maupun ABPD. Maka penonaktifan kartu peserta BPJS dari Pusat tentu berpengaruh bagi setiap daerah terutama pemegang Kartu BPJS PBI di kota Medan, karena Pemerintah kota Medan sejak tahun 2015 lalu memberlakukan kartu Medan sehat menjadi kartu peserta BPJS untuk memberikan manfaat perlindungan kesehatan bagi masyarakat miskin kota Medan. Perubahan data tersebut tidak dilakukan sosialisasi sehingga peserta PBI tidak mengetahui adanya dan alasan perubahan data. Oleh karena itu, rumusan masalah yaitu sebab perubahan data fakir miskin peserta PBI dan bagaimana perlindungan hukum terhadap jaminan kesehatan bagi masyarakat miskin di Kota Medan. Tujuan penelitian untuk memberikan perlindungan hukum yang diberikan pemerintah daerah kota Medan kepada Peserta PBI yang dinonaktfikan. Jenis penelitian menggunakan jenis penelitian yuridis normatif-empiris. Hasil penelitian dimana sebab perubahan data Peserta PBI menjadi non PBI sebagai penyesuaian anggaran belanja baik APBN atau APBD Propinsi dan kabupaten/kota dan perlindungan hukum fakir miskin pasien PBI merupakan kewajiban pemerintah dengan melakukan pendataan ulang kriteria fakir miskin yang dilakukan oleh Dinas Sosial Kota Medan. Dinsos akan memberikan surat keterangan miskin (SKM) kepada Peserta PBI yang dinonaktifakn guna untuk mengaktfkan kembali menjadi peserta PBI di kantor BPJS Kesehatan. Kesimpulan yaitu perubahan data terjadi karena mengefisiensi dana dari APBN maupun APBD, perubahan tersebut juga didasarkan Keputusan Menteri Sosial RI Nomor: 146 / HUK / 2013 tentang Penetapan Kriteria dan Pendataan Fakir Miskin dan Orang Tidak Mampu, upaya perlindungan hukum merupakan perlindungan secara preventif tujuan mencegah terjadinya pelanggaran terlebih dahulu dengan melakukan sosialisasi atau pendataan ulang setiap tahunnya untuk memastikan kelayakan peserta PBI.
\end{abstract}

Kata kunci: perlindungan hukum, BPJS kesehatan, peserta PBI, dinas sosial kota medan, fakir miskin. 


\title{
Legal Protection Againt Changes in Poor Data of Disabled Contribution Assistance Recipients Become Non-Recipients of Contribution Assistance (Study of Social Service Medan City)
}

\begin{abstract}
The Ministry of Social Affairs issued a Decree (SK) of the Minister of Social Affairs Number 79/2019 for the sixth phase, as of August 1/2019. The Ministry of Social Affairs has deactivated as many as 5,227,852 million participants of the Social Security Administering Body (BPJS) of Health Contribution Assistance Recipients (PBI). The reason's the budget deficit of APBN and $A B P D$. The deactivation of BPJSparticipant cards from the Center certainly affects every region, especially bpjs pbi card holders in Medan, because the Medan government since 2015 then enacted a healthy Medan card. The change wasn't socialized so that PBIparticipants weren't aware of the existence and reason for the data change. The problem's the reason for the change in the data of poor PBIparticipants and how the legal protection of health insurance for the poor in Medan. The study purpose is to find out the legal protection provided by the medan government to PBIparticipants who don't have batteries. The results of the study where because of changes in data of PBIParticipants to nonPBI as an adjustment to the budget of both the State Budget or APBD of provinces and districts/cities and the protection of the law of the poor patients PBI's the obligation of the government by re-data collection criteria of the poor conducted by the Social Service of Medan City. Dinsos will provide poor certificate (SKM) to pbi participants who are disabled in order to re-become PBIparticipants in BPJS Health office. The conclusion's that data change occurred because of the efficiency of funds from the State Budget and APBD, the changes also based on the Decree of the Indonesian Minister of Social Affairs Number:146/HUK/2013, legal protection efforts are preventive protection of the purpose of preventing violations in advance by conducting socialization or re-data collection everyyear to ensure the feasibility of PBIparticipants.
\end{abstract}

Keywords: legal protection, BPJS health, PBI participants, social services of medan city, poor people.

\section{Pendahuluan}

Kesejahteraan sosial dimaksud yaitu merupakan kondisi terpenuhi kebutuhan materill, sepritual, dan sosial sehingga warga Negara dapat menjalankan kehidupan yang layak dan bisa mengembangkan diri agar dapat melaksanakan fungsi sosial. Tujuan sistem kesejahteraan dalam program kesejahteraan sosial menurut Scheneidermen adalah: 
1. Mencapai kehidupan sejahtera dimana tercapainya standart kehidupan pokok yaitu sandang, pangan, papan dan kesehatan serta hubungan sosial yang harmonis dengan lingkungan.

2. Mencapai penyesuaian diri yang baik khususnya dengan masyarakat di lingkungan sekitar (Ari, 2012:10).

Dalam rangka menciptakan kesejahteraan sosial bagi seluruh rakyat Indonesia tentunya pemerintah mempunyai program terencana dalam mewujudkan hal tersebut sebagai bentuk jaminan perlindungan baik kesehatan maupun pemberdayaan sumber daya manusia. Kesejahteraan sosial dimanfaatkan meningkatkan kualitas hidup melalui pengelolaan permasalahan sosial dalam hal pemenuhan kebutuhan hidup masyarakat dimana terdorong untuk mencapai kehidupan lebih baik (Sadi, 2017). Pemenuhaan kebutuhan hidup dimaksud untuk masyarakat meliputi materill, spirituall dan sosial untuk meningkatkan taraf hidup dalam perkembangan sosial masyarakat. Bentuk jaminan perlindungan kesehatan merupakan wujud dari program pemerintah yang diberikan kepada masyarakat. Program jaminan kesehatan tersebut ada yang bersifat mandiri (biaya pribadi) dan bersifat subsidi Pemerintah disebut penerima bantuan iuran (PBI).

Pada Tahun 2019 Kementerian Sosial mengeluarkan Surat Keputusan Menteri Sosial (SK Kemensos) Nomor 76 Tahun 2019 bagi masyarakat miskin atau orang tidak mampu. Pertanggal 01 Agustus 2019 terdapat sejumlah peserta tidak terdaftar kembali menjadi peserta PBI jaminan kesehatan. Kementerian Sosial (Kemensos) telah menonaktifkan sebanyak 5.227.852 juta peserta Badan Penyelenggara Jaminan Sosial (BPJS) Kesehatan Penerima Bantuan Iuran (PBI). Kebijakan penonaktifan kartu BPJS dari Pusat ini dilakukan secara sepihak. Karena tidak dikoordinasikan terlebih dahulu dengan pemerintah daerah (PEMDA). Langkah pemerintah menonaktifkan kepesertaan 5,2 juta peserta PBI BPJS Kesehatan juga menuai soroton dari Yayasan Lembaga Konsumen Indonesia (YLKI) maupun Jamkes Watch selaku lembaga pengawas pelaksanaan Jaminan Kesehatan Nasional (JKN) yang dibentuk Konfederasi Serikat Pekerja Indonesia (KSPI) (Zaeni, 2017). 
Penonaktifan Kartu BPJS dari Pusat tentu juga berpengaruh bagi pemegang Kartu Medan Sehat di kota Medan, karena Pemerintah kota Medan selama ini memberlakukan kartu Medan sehat yang memberikan manfaat Perlindungan Kesehatan bagi warga kota Medan, Sejak Tahun 2015 lalu para pemegang kartu Medan Sehat otomatis masuk menjadi peserta Badan Penyelenggara Jaminan Sosial (BPJS) sesuai Perpres RI Nomor 111 tahun 2013 Pasal 6, Kepesertaan Jaminan kesehatan bersifat wajib dan mencakup seluruh penduduk Indonesia.

Namun untuk mengidentifikasi data masyarakat miskin tersebut tentunya butuh kriteria pendataan yang akurat agar tepat sasaran. Hal ini perlu dilakukan agar masyarakat miskin yang terdaftar sebagai PBI tidak hilang haknya untuk menerima bantuan iuran jaminan kesehatan. Untuk di kota Medan tentunya memberikan dampak bagi masyarakat miskin yang tidak memahami akan adanya penonaktifan, dimana diwaktu yang sama masyarakat tersebut akan sedang membutuhkan fasilitas kesehatan melalui pelayanan PBI. Perubahan dan penonaktifan data PBI tentunya akan berpengaruh bagi masyarakat miskin yang membutuhkan jaminan kesehatan, yang mana BPJS atau Kemensos tidak terlebh dahulu melakukan sosialisasi secara aktif agar masyarakat memahami apa yang perlu dilakukan untuk memperoleh haknya. Penonaktifan kepesertaan PBI pasca dikeluarkannya, hal ini tentunya perlu menjadi perhatian bagi pemerintah dalam meningkatkan dan memberikan perlindungan jaminan kesehatan dan pelayanan kesehatan bagi masyarakat miskin (Lestari, 2018).

Perubahan data tersebut menjadi salah satu kewajiban negara dengan melindungi setiap warga negaranya baik secara fisik, mental, sosial dan ekonomi sesuai dengan kondisi kemampuan keuangan negara, Indonesia seperti halnya berbagai negara berkembang lainnya, mengembangkan program Jaminan Kesehatan Nasional (M. Pertiwi \& Nurcahyanto, 2017). Di bidang kesehatan, Pasal 14 UU No. 36 Tahun 2009 tentang Kesehatan menyatakan bahwa pemerintah bertugas menyelenggarakan upaya kesehatan yang merata dan terjangkau oleh masyarakat. Wujud dari bentuk perlindungan yang diberikan Pemerintah maka seluruh Warga Negara Indonesia wajib mendaftarkan diri dan seluruh anggota keluarganya ke dalam program jaminan kesehatan nasional dari 
pemerintah, yaitu BPJS Kesehatan dan BPJS Ketenagakerjaan. Kewajiban kepesertaan mengikuti program jaminan kesehatan BPJS ditegaskan lagi dalam Penjelasan Pasal 4 huruf g UU No. 24 Tahun 2011 tentang BPJS yang menyatakan yang dimaksud prinsip kepesertaan bersifat wajib mengharuskan seluruh penduduk menjadi peserta jaminan sosial dilaksanakan secara bertahap. Pemohon tidak ikut asuransi BPJS Kesehatan akan terkena sanksi oleh BPJS baik teguran tertulis, denda, hingga tidak mendapat pelayanan publik tertentu yang dijelaskan Pasal 17 UU BPJS.

Sesuai dengan UU Nomor 40 Tahun 2004 tentang Sistem Jaminan Sosial Nasional, setiap orang berhak atas jaminan sosial untuk dapat memenuhi kebutuhan dasar hidup yang layak. Untuk memberikan jaminan sosial yang menyeluruh, maka negara mengembangkan Sistem Jaminan Sosial Nasional bagi seluruh rakyat Indonesia yang bersifat wajib.

Undang-Undang Nomor 23 tahun 1992 tentang Kesehatan memberikan perlindungan hukum, baik kepada pasien sebagai penerima (konsumen) jasa pelayanan kesehatan dan pemberi (produsen) jasa pelayanan kesehatan. Karena kedudukan pasien adalah sebagai konsumen jasa, maka ia juga mendapatkan perlindungan sesuai dengan Undang-Undang Nomor 8 Tahun 1999 tentang Perlindungan Konsumen.

Berdasarkan permasalahan tersebut perlu adanya perhatian dan perlindungan hukum dari pemerintah dalam hal mendata masyarakat fakir miskin yang telah terdaftar, namun karena adanya Surat Keputusan Menteri Sosial Nomor 76 Tahun 2019 Tentang Penonaktifan Dan Perubahan Data Peserta PBI Jaminan Kesehatan Tahun 2019 tentunya akan mempengaruhi hak sipil bagi masyarakat miskin untuk memperoleh jaminan kesehatan.

Adapun rumusan masalah yang akan dibahas dalam artikel ini adalah sebagai berikut:

1. Apa yang menyebabkan perubahan data fakir miskin peserta PBI yang dinonaktifkan menjadi peserta PBI di Kota Medan?

2. Bagaimana perlindungan hukum terhadap jaminan kesehatan masyarakat miskin di Kota Medan? 
Metode penelitian yang digunakan yaitu jenis penelitian normative-empiris yang merupakan suatu metode penelitian yang menggabungkan unsur hukum normatif kemudian didukung dengan penambahan data atau unsur empiris. Penelitian yuridis normative dilakukan melalui penelahanan terhadap teori-teori, penelahan dilokasi penelitian, dilakukan bertujuan mengetahui hukum dalam kenyataan baik berupa penelitian, pendapat, data yang berkaitan dengan dampak dikeluarkannya SK Menteri Sosial No. 79 Tahun 2019 tentang Penonaktifan dan Perubahan Data Peserta PBI Jaminan Kesehatan Tahun 2019 Tahap ke enam.

Data digunakan penelitian adalah data primer dan sekunder dengan lokasi penelitian dilakukan pada Kantor Dinas Sosial Kota Medan dan Rumah Sakit Pirngadi Medan. Teknik pengumpulan data penelitian adalah studi dokumen dengan mengumpulkan data dari instansi, artikel/jurnal serta pendapat para ahli dan melakukan instrumen wawancara, baik terstruktur maupun tidak terstruktur. Informan yang diwawancarai antara lain, Dinas Sosial Kota Medan bagian jaminan sosial keluarga dan pihak rumah sakit Pirngadi bagian instalisai verifikasi asuransi kesehatan di Rumah Sakit Pirngadi.

Pengolahan data dilakukan dengan cara data kualitatif dimana data dikumpulkan kemudian diolah melalui tiga cara yaitu persiapan, pengolahan, dan penarikan kesimpulan, yakni proses pengolahan data tahap akhir melalui penarikan kesimpulan untuk mengetahui apakah data tersebut dapat dilanjutkan pada tahap analisis. Analisis data menggunakan pendekatan penelitian deskriptif kualitatif yang dimana dilakukan dengan cara mendeskripsikan (menggambarkan/menceritakan) kembali secara tertulis hasil survey lapangan.

\section{Pembahasan}

A. Penyebab perubahan data fakir miskin peserta PBI yang dinonaktifkan menjadi peserta PBI di Kota Medan

\section{Sebab Penonaktifan Peserta BPJS Kesehatan PBI Menjadi Non PBI}

Pemerintah menerbitkan Peraturan No. 101 Tahun 2012 tentang PBI pada tahun 2012 lalu. Peraturan tersebut intinya mengatur tentang siapa yang berhak menerima bantuan pembayaran iuran jaminan kesehatan (PBI 
JK) dari pemerintah yang disubsidi dari anggaran APBN maupun APBD. Jaminan kesehatan dimulai pada 01 Januari 2014. Dalam peraturan PBI JK ditujukan untuk fakir miskin dan masyarakat tidak mampu. Katagori peserta BPJS kesehatan PBI adalah peserta yang termasuk katagori rakyat miskin dimana sudah tertuang dalam Keputusan Menteri Sosial Republik Indonesia No. 146/HUK/2013 tentang Penetapan Kriteria dan Pendataan Fakir Miskin dan Orang Tidak Mampu. Perubahan pasien PBI menjadi Non PBI merupakan kebijakan KEMENSOS dimana Pemerintah melakukan pembaharuan data peserta PBI JK secara berkala dan langkah ini harus dilakukan agar data PBI tepat sasaran.

Hasil wawancara pada tanggal 24 Agustus 2020 oleh Bapak Arianto jabatan kepala seksi jaminan sosial keluarga dinas sosial kota medan beliau mengatakan bahwa perubahan peserta PBI menjadi Non PBI mengingat dana dari APBN maupun APBD dan penetapan peserta PBI JK mengacu pada data terpadu kesejahteraan sosial atau disebut DTKS. Hal ini perlu di dukung dari semua pihak terkait sehingga penyempuranaan DTKS terus dapat dilaksanakan dan DTKS terbit setiap enam bulan sekali. DTKS yang terbit pada Januari 2020 jumlahnya 97,3 juta jiwa, hal ini perlu dilakukan sosialisasi secara terus-menerus dan menyeluruh agar masyarakat mengetahui apakah dia dan anggota keluarganya terdaftar atau tidak dalam DTKS.

Adapun sebab penonaktifkan peserta PBI JK disebabkan tidak terdaftar di data terpadu. Peserta dalam hal ini perlu didorong untuk proaktif melaporkan ke dinas sosial setempat apabila terjadi ketidaksingkronan terhadap data. Oleh karena itu, diharapkan peserta segera melaporkan data diri dan anggota keluarganya ke Dinas Sosial setempat untuk pemutakhiran atau pengecekan DTKS.

Adapun data jumlah perubahan peserta PBI pada tahun 2019 berdasarkan SK Kemnsos No. 76 Tahun 2019 Tentang Penonaktifan Dan Perubahan Data Peserta PBI Jaminan Kesehatan Tahun 2019 yaitu sebagai berikut: 
Tabel 1. Data Jumlah Perubahan Peserta PBI Pada Tahun 2019 Berdasarkan SK Kemnsos No. 76 Tahun 2019

\begin{tabular}{|c|c|c|c|}
\hline No & Kode Provinsi & Provinsi & Jumlah \\
\hline 1 & 11 & Aceh & 200.017 \\
\hline 2 & 12 & Sumatera Utara & 256.107 \\
\hline 3 & 13 & Sumatera Barat & 100.479 \\
\hline 4 & 14 & Riau & 107.744 \\
\hline 5 & 15 & Jambi & 70.414 \\
\hline 6 & 16 & Sumatera Selatan & 197.736 \\
\hline 7 & 17 & Bengkulu & 46.125 \\
\hline 8 & 18 & Lampung & 162.291 \\
\hline 9 & 19 & Kepulauan Bangka Belitung & 12.096 \\
\hline 10 & 21 & Kepulauan Riau & 39.654 \\
\hline 11 & 31 & DKI Jakarta & 54.961 \\
\hline 12 & 32 & Jawa Barat & 923.895 \\
\hline 13 & 33 & Jawa Tengah & 521.997 \\
\hline 14 & 34 & DI Yogyakarta & 107.603 \\
\hline 15 & 35 & Jawa Timur & 835.463 \\
\hline 16 & 36 & Banten & 283.509 \\
\hline 17 & 51 & Bali & 47.728 \\
\hline 18 & 52 & NTB & 177.589 \\
\hline 19 & 53 & NTT & 278.606 \\
\hline 20 & 61 & Kalimantan Barat & 102.540 \\
\hline 21 & 62 & Kalimantan Tengah & 25.022 \\
\hline 22 & 63 & Kalimantan Selatan & 18.129 \\
\hline 23 & 64 & Kalimantan Timur & 35.406 \\
\hline 24 & 65 & Kalimantan Utara & 19.601 \\
\hline 25 & 71 & Sulawesi Utara & 37.436 \\
\hline 26 & 73 & Sulawesi Tengah & 95.714 \\
\hline 27 & 73 & Sulawesi Selatan & 172.718 \\
\hline 28 & 74 & Sulawesi Tenggara & 74.903 \\
\hline 29 & 75 & Gorontalo & 30.397 \\
\hline 30 & 76 & Sulawesi Barat & 15.313 \\
\hline 31 & 81 & Maluku & 140.884 \\
\hline 32 & 82 & Maluku Utara & 33.326 \\
\hline 33 & 91 & Papua Barat & 1.099 \\
\hline 34 & 94 & Papua & 1800 \\
\hline \multicolumn{3}{|c|}{ Jumlah } & 5.227 .852 \\
\hline
\end{tabular}

Sumber: Surat Keputusan Menteri Sosial No. 76/2019 Tentang Penonaktifan dan Perubahan Data Peserta PBI Jaminan Kesehatan Tahun 2019 Tahap Ke-6.

Hasil wawancara pada tanggal 24 Agustus 2020 oleh Bapak Arianto jabatan kepala seksi jaminan sosial keluarga dinas sosial kota medan beliau mengatakan, perubahan PBI menjadi Non PBI di tahun 2019 untuk sumatera utara berjumlah 256.107. Perubahan tersebut terjadi adanya 
penyesuaian dana dari APBN maupun APBD yang diterima sehingga subsidi pemerintah untuk peserta PBI berubah dari tahun sebelumnya. Perubahan pasien PBI menjadi Non PBI merupakan kebijkan kementerian sosial dimana pemerintah melaksanakan pembaharuan data peserta PBI JK secara berkala (A. Pertiwi, 2016).

Berdasarkan hasil wawancara dengan Bapak Dr. Hendrico H.P Simarmata selaku sebagai kepala instalisai verifikasi asuransi kesehatan di Rumah Sakit Pirngadi mengatakan, tentang penonaktifan PBI menjadi Non PBI mulai diberlakukan terhitung 1 agustus 2019 sesuai dengan terbitnya SK Kemensos No. 79 Tahun 2019 tentang Penonaktifan dan Perubahan Data Peserta PBI JK Tahun 2009 Tahap Ke-enam. Perubahan terjadi mengingat dana dari APBN maupun APBD. Perubahan tersebut dilakukan antara kementerian sosial dengan kementerian kesehatan. Pihak rumah sakit tidak mengetahui secara signifikan perubahan data pasien PBI menjadi Non PBI, pihak rumah sakit hanya menerima data dan jika terjadi perubahan peserta maka peserta akan diberi petunjuk untuk melaporkan ke PBJS.

Perubahan data tersebut berdampak kepada masyarakat miskin peserta PBI yang berubah data menjadi peserta non PBI. Dimana dampak dari perubahan tersebut yaitu hak-hak peserta PBI dalam menerima jaminan kesehatan tidak dapat dinikmati kembali. Semakin meningkat tingkat kematian maupun penyakit masyarakat miskin yang dimana mereka tidak mampu untuk melakukan pembayaran secara mandiri. Selain itu, perubahan tersebut dikarenakan salah satu keluarga tidak melaporkan perubahan kartu keluarga dimana ada keluarga yang sudah meninggal dunia, menikah atau cerai sehingga dampaknya tidak melapor atas perubahan tersebut tidak terdaftar menjadi peserta PBI. Dan dampak ke pihak rumah sakit lebih ke sistem rumah sakit dimana pihak rumah sakit melakukan penjelasan kepada peserta PBI yang ingin berobat atau sudah rawat inap karena tidak ada sosialisasi dari pemerintah.

Solusi dari perubahan data yaitu jika dari peserta yang tidak melaporkan terhadap perubahan kartu keluarga seperti salah satu anggota 
keluarga meninggal dunia, menikah ataupun bercerai maka solusinya peserta harus melaporkan perubahan ke instansi terkait sehingga akan dilakukan perubahan oleh pemerintah. Selain itu, pemerintah harus melakukan sosialisasi secara luas dan terbuka tentang perubahan data dan menginformasikan tentang syarat menjadi peserta PBI. Melakukan pendataan ulang dengan terjun ke lapangan sehingga subsidi pemerintah untuk kesehatan sampai pada masyarakat yang membutuhkan.

Pihak yang berwenang untuk menetapkan kriteria fakir miskin dan orang tidak mampu yaitu kemensos setelah melakukan koordinasi dengan Menteri dan/atau pimpinan lembaga terkait. Antara lain Kementerian Kesehatan, Kementerian Tenaga Kerja dan Transmigrasi serta Kementerian Dalam Negeri. Nantinya, kriteria yang sudah ditetapkan oleh Kementerian tersebut ditindaklanjuti oleh Badan Pusat Statitistik (BPS) dengan melakukan pendataan. Kementerian Kesehatan lantas menindaklanjuti data dari BPS itu dengan menyampaikannya kepada Badan Penyelenggara Jaminan Sosial (BPJS) Kesehatan. BPJS Kesehatan lantas memberikan nomor identitas tunggal kepada para penerima bantuan iuran.

\section{Pendataan Masyarakat Miskin}

Pemberian jaminan kesehatan merupakan hak semua masyarakat dalam kebutuhan hidup yang layak untuk mendapatkan pelayanan kesehatan. (Sulastomo, 2012: 12). Salah satunya hak fakir miskin dalam mendapatkan pelayanan kesehatan. Untuk mengetahui penduduk miskin di Kota Medan dan berhak mendapatkan jaminan kesehatan yang dibiayai oleh pemerintah Kota Medan harus dilakukan pendataan terlebih dahulu yang dilakukan oleh Dinas Sosial Kota Medan

Hasil wawancara pada tanggal 24 Agustus 2020 oleh Bapak Arianto jabatan kepala seksi jaminan sosial keluarga Dinas Sosial Kota Medan beliau mengatakan pendataan fakir miskin yang dinyatakan fakir miskin ada 14 katagori dan pendataan tersebut ikut diperbantukan oleh lurah dan kepala lingkungan sekitar. Adapun katagori fakir miskin diatur di dalam Keputusan Menteri Sosial Republik Indonesia No. 146/HUK/2013 tentang Penetapan 
Kriteria dan Pendataan Fakir Miskin dan Orang Tidak Mampu, terdiri atas 14 kriteria miskin, meliputi:

a. Luas lantai bangunan tempat tinggal kurang dari $8 \mathrm{M} 2$;

b. Lantai tempat tinggal terbuat dari tanah/ bamboo/ kayu murahan;

c. Jenis dinding tempat tinggal terbuat dari bamboo/ rumbia/ kayu berkualitas rendah/ tembok tanpa plaster;

d. Tidak memiliki fasiltas buang air besar/bersama-sama dengan rumah tangga lain;

e. Sumber penerangan rumah tidak menggunakan listrik;

f. Sumber air minum berasal dari sumber/mata air tidak terlindung/ sungai/ air hujan;

g. Hanya mengkonsumsi daging/ susu/ ayam dalam sekali seminggu;

h. Hanya membeli satu pakaian baru dalam setahun;

i. Hanya sanggup makann sebanyak sekali/ dua kali dalam sehari;

j. Tidak sanggup membayar biaya pengobatan di puskesmas/ klinik;

k. Sumber penghasilan kepala rumah tangga adalah petani dengan luas lahan 500M2, buruh tani, nelayan, buruh bangunan, buruh perkebunan dan atau pekerjaan lainnya dengan pendapatan di bawah Rp. 600.000,per bulan;

1. Pendidikan tertinggi kelapa rumah tangga tidak sekolah/ tidak tamat $\mathrm{SD} /$ tamat SD;

m. Tidak memiliki tabungan/ barang yang mudah dijual dengan minimal Rp. 500.000,- seperti sepeda motor kredit/non kredit, emas, ternak, kapal motor, atau barang modal lainnya.

Berdasarkan hasil wawancara kasi jaminan sosial keluarga dinas sosial kota medan Bpk Arianto bahwa katagori miskin terdapat di dalam peraturan Keputusan Menteri Sosial Republik Indonesia Nomor: 146/HUK/2013 tentang Penetapan Kriteria dan Pendataan Fakir Miskin dan Orang Tidak Mampu. Namun, fakta di lapangan tidak sebagian katagori fakir miskin tersebut di atas terpenuhi semua di kota Medan. Sebab untuk menemukan terpenuhi semua sangatlah sulit, dikarenakan untuk saat ini sulit menemukan kriteria seperti jenis lantai dari tanah, dinding berupa bambu ataupun kayu murahan, sumber penerangan tidak menggunakan listrik, tidak ada fasilitas buang air dan terdapat diluar, sumber air minum berasal dari sumur/sungai, serta bahan bakar memasak sehari-hari adalah kayu bakar atau minyak tanah. Apabila dari 9 katagori termasuk katagori maka 
dapat dikatogorikan fakir miskin. Adapun data persentase penduduk miskin kota medan diperoleh dari tahun 2016-2020 melalui Dinas Sosial Kota Medan dari Badan Pusat Statistik yaitu:

Tabel 2. Data Persentase Jumlah Masyarakat Miskin Kota Medan 2016-2020

\begin{tabular}{|c|c|c|c|c|c|}
\hline \multirow{2}{*}{ Provinsi } & \multicolumn{5}{|c|}{ Jumlah Penduduk Miskin (Ribu Jiwa) } \\
\cline { 2 - 6 } & 2019 & 2018 & 2017 & 2016 & 2015 \\
\hline \multirow{2}{*}{ Sumatera Utara } & 1282,04 & 1325,00 & 1454,00 & - & - \\
& $(8,83 \%)$ & $(9,22 \%)$ & $(10,22 \%)$ & $(10,35 \%)$ & $(10,53 \%)$ \\
\hline
\end{tabular}

\begin{tabular}{|c|c|c|c|c|c|}
\hline \multirow{2}{*}{ Kabupaten/Kota } & \multicolumn{5}{|c|}{ Jumlah Penduduk Miskin (Ribu Jiwa) } \\
\cline { 2 - 6 } & 2019 & 2018 & 2017 & 2016 & 2015 \\
\hline \multirow{2}{*}{ Kota Medan } & $\begin{array}{c}183,79 \\
(8,08 \%)\end{array}$ & $\begin{array}{c}186,45 \\
(8,25 \%)\end{array}$ & $\begin{array}{c}204,22 \\
(9,11 \%)\end{array}$ & $\begin{array}{c}206,87 \\
(9,30 \%)\end{array}$ & $\begin{array}{c}207,50 \\
(9,41 \%)\end{array}$ \\
\hline
\end{tabular}

Sumber: Data dari Dinas Sosial Kota Medan yang diperoleh oleh Badan Pusat Statistik.

Jumlah penduduk/masyarakat miskin di kota Medan dari tahun 2015 sampai tahun 2019 menurun walaupun tidak secara signifikasi. Dimana tahun 2019 jumlah penduduk miskin kota Medan sebanyak 183,79 ribu jiwa atau sekitar 8,08 persen dari total jumlah penduduk. Angka tersebut turun tipis diibanding tahun sebelumnya sebanyak 186,45 ribu jiwa. Sementara tahun 2017 jumlah penduuduk miskin di kota Medan sebanyak 204,22 ribu jiwa. Kondisi ini diperburuk oleh keadaan adanya krisis ekonomi yang melanda, ditandai tidak stabilnya kondisi perekonomian.

Berdasarkan hasil wawancara dengan kepala seksi jaminan sosial keluarga dinas sosial kota medan Bpk Arianto dalam hal ini ada beberapa faktor yang menyebabkan angka kemiskinan di kota Medan masih tinggi yaitu faktor pertumbuhan ekonomi yang belum stabil dengan pembangunan yang masih belum merata, insfraktuktur yang tidak baik sehingga banyak perbaikan-perbaikan dan mengeluarkan dana APBD yang begitu banyak. Rendahnya pendidikan keterampilan kerja menjadi alasan sehingga terbatasnya ketersediaan lapangan kerja. Maka angka pengangguran juga bertambah banyak. Apalagi di tengah pandemic Covid19 saat ini, jumlah angka kemiskinan di tahun 2020 pasti akan bertambah, seiring dengan menurunnya pendapatan masyarakat dan pertambahan angka pengangguran. 


\section{B. Perlindungan Hukum Terhadap Jaminan Kesehatan Bagi Masyarakat Miskin di Kota Medan}

\section{Perlindungan Hukum Terhadap Jaminan Kesehatan Bagi Masyarakat Miskin di Kota Medan}

Kepesertaan Penerima Bantuan Iuran Jaminan Kesehatan yang disingkat (Peserta PBI JK) adalah jaminan kesehatan bagi fakir miskin dan masyarakat tidak mampu yang diamanatkan dalam Undang-undang sistem jaminan sosial, dimana iuran tersebut dibayar oleh pemerintah (BPJS, 2018: 17). Iuran yang dibayar pemerintah kepada BPJS, Bapak Ardianto mengatakan iuran yang dibayarkan pemerintah kepada BPJS untuk peserta PBI bersumber dari salah satu dari tiga sumber anggaran yaitu anggaran penerimaan balanja negara, anggaran penerimaan belanja daerah propinsi, anggaran belanja daerah kabupaten kota. Namun terjadinya perubahan data yang dikeluarakan oleh Kementerian Sosial bagi peserta PBI menyebabkan masyarakat tidak dapat memperoleh haknya sebagai peserta PBI, hal ini menimbulkan polemik dimasyarakat itu sendiri.

Perubahan data penerima PBI tanpa adanya pemberitahuan ataupun sosialisai dari pihak terkait mengakibatkan kesulitan bagi masyarakat miskin yang secara tiba-tiba membutuhkan pelayanan kesehatan. Tujuan dari perubahan data tersebut menurut Ardianto sebagai penyesuaian anggaran belanja baik APBN atau APBD Propinsi dan kabupaten/kota. Hal ini tentu perlunya perlindungan hukum bagi peserta yang data kepesertaan PBI yang dinon-aktifkan. Dalam memberikan perlindungan hukum ada suatu hal yang dilindungi yaitu melindungi subyek-subyek hukum melalui peraturan perundang-undangan yang berlaku dan dipaksakan pelaksanaannya dengan suatu sanksi (Muchsin, 2003:14).

Menurut Muchsin perlindungan hukum dibagi menjadi dua yaitu perlindungan hukum preventif dan perlindungan hukum represif. Perlindungan hukum yang diberikan untuk mencegah terjadinya suatu sanksi di dalam perubahan data Pasien PBI dapat dilakukan perlindungan hukum secara preventif dimana perlindungan yang diberikan oleh 
pemerintah dengan tujuan untuk mencegah sebelum terjadinya pelanggaran (Sulastamo, 2011). Hal ini terdapat dalam peraturan perundang-undangan dengan maksud untuk mencegah suatu pelanggaran serta memberikan rambu-rambu atau batasan-batasan dalam melakukan suatu kewajiban. Dalam hal ini pemerintah memberikan pemberitahuan atau sosialisasi secara merata tentang informasi perubahan data Peserta PBI yang dilakukan oleh Kementerian Kesehatan dan Kementerian Sosial sehingga dapat mencegah kerugian atau kesenjangan hak yang di dapatkan oleh Peserta BPJS PBI. Dan juga memberikan dan menjelaskan tentang perubahan peraturan yang terjadi dan tindak lanjut jika Peserta PBI merupakan masyarakat fakir miskin namun terjadi perubahan menjadi Peserta Non PBI. Perlindungan hukum secara preventif diberikan bertujuan agar tidak terjadi sengketa sampai di pengadilan dan menghindari sanksi serta denda (Putri \& Murdi, 2019).

Pentingnya perlindungan hukum secara preventif bagi peserta BPJS PBI sebagi wujud perlindungan hak bagi masyarakat miskin yang membutuhkan pelayanan kesehatan. Secara hukum, perlindungan ini tidak sebatas hanya pelayanan kesehatan yang dilakukan oleh rumah sakit ataupun tenaga medis melainkan hak bagi peserta memperoleh informasi terkait kepesertaannya sebagai PBI. Perubahan data yang mengakibatkan non aktifnya kepesertaan PBI bagi masyarakat miskin tentunya dapat menimbulkan polemik dimasyarakat dalam bentuk keadilan yang diberikan negara terhadap masyarakat. Perlindungan hukum yang dirasakan oleh masyarakat miskin tentunya dapat dilaksanakan sebagaimana dengan tujuan hukum itu sendiri, yaitu mengatur tata tertib masyarakat secara damai dan adil, serta melindungi kemerdekaan, kehormatan, jiwa, harta dari sesuatu yang merugikan.

Perlindungan hukum terhadap masyarakat miskin akibat dari nonaktifnya kepesertaan BPJS adalah tanggung jawab pemerintah, melalui Dinas Sosial Kota Medan tentunya pemerintah mampu memberikan hak masyarakat miskin dalam memperoleh pelayanan kesehatan. Berdasarkan 
penelitian yang dilakukan di Kantor BPJS Medan bahwasanya BPJS hanya menjalankan program pemerintah sebagai penyelenggara jaminan sosial kesehatan dari data yang diserahkan pemerintah yang nantinya dijadikan sebagai peserta PBI BPJS yang berhak menerima pelayanan kesehatan sebagaimana telah diatur dalam undang-undang. Data kepesertaan BPJS tersebut bersumber dari Dinas Sosial yang diperoleh dari pusat data di Kementerian Sosial.

Perlindungan hukum tentang peseta BPJS PBI bukan hanya merupakan tanggung jawab pemerintah Kemeterian Sosial dan Dinas Sosial saja, namun Kementrian Kesehatan juga bertanggung jawab dalam perlindungan peserta BPJS dimana di dalam Undang-undang 36 Tahun 2009 tentang Kesehatan Pasal 4 ayat 1 menyatakan "Setiap orang berhak atas kesehatan" dan Pasal 5 (1) menyatakan "Setiap orang mempunyai hak yang sama dalam memperoleh akses atas sumber daya di bidang kesehatan”.

Selain itu, peserta BPJS PBI sebagai pasien juga merupakan konsumen. Dimana peserta PBJS merupakan konsumen yang menggunakan layanan kesehatan rumah sakit. Di dalam layanan BPJS, manfaat serta pelayanan BPJS berbeda dari asuransi swasta serta askes, bisa dibedakan dalam hal penerapa pelayanan kesehatan bejenjang. Peserta BPJS diharuskan terlebih dahulu ke fasilitas kesehatan tingkat I yang ditunjuk yaitu klinik, puskesmas, dokter untuk mendapatkan surat rujukan. Kecuali gawat darurat peserta dapat langsung pergi kerumah sakit apabila BPJS tersebut bekerja sama dengan rumah sakit yang terkait perlindungan hukum yang diberikan terkait hak-hak pasien sebagai konsumen.

Hak pasien sebagai konsumen diatur di dalam Undang-undang No. 8 Tahun 1999 tentang Perlindungan konsumen Pasal 4 butir 1 yang menyebutkan: "Hak atas kenyamanan, keamanan, dan keselamatan dalam mengkonsumsi barang dan/atau jasa", Pasal 4 butir 2 yang menyebutkan "Hak atas informasi yang benar, jelas dan jujur mengenai kondisi dan jaminan barang dan/atau jasa", dan Pasal 4 butir 3 yang menyebutkan "Hak 
untuk mendapatkan advokasi, perlindungan dan upaya penyelesaian sengketa perlindungan konsumen secara patut”.

Berdasarkan keterangan diatas, peserta PBI sebagai pasien berhak mendapatkan perlindungan dalam keselamatan, informasi yang benar tentang keanggotaan peserta apakah aktif menjadi peserta PBI atau sebaliknya, berhak mendapatkan advokasi atau perlindungan lembaga hukum dan perlindungan dalam upaya sengketa jika peserta BPJS tidak dilayanai sebagaimana semestinya dan hak-hak pasien diatur dalam ketentuan peraturan perundang-undangan lainnya salah satunya undangundang rumah sakit dan kesehatan. Adapun tempat pengaduan konsumen terdapat di lembaga perlindungan konsumen yaitu Lembaga Yayasan Konsumen Indonesia (YLKI).

Oleh karena itu, perlindungan hukum peserta PBI harus dilakukan secara preventif yaitu perlindungan untuk mencegah terjadinya pelanggaran terlebih dahulu. Dilakukan sosialisasi dari Kementerian Kesehatan, Kementerian Sosial dan BPJS Kesehatan kepada peserta BPJS baik PBI maupun Non PBI untuk menghindari kerugian dari hak-hak pasien PBI maupun Non PBI.

Hasil wawancara oleh Bapak Arianto jabatan kepala seksi jaminan sosial keluarga dinas sosial kota medan beliau menerangkan jika peserta PBI telah nonaktif kepesertaanya dikarenakan perubahan data dari surat keputusan ini, maka Dinas Sosial Kota Medan akan membuka data masyarakat miskin pada data terpadu kesejahteraan sosial yang terdaftar di Dinas Sosial Kota Medan, jika yang bersangkutan terdaftar didata terpadu kesejahteraan sosial, berdasarkan hal tersbut dinas sosial Kota Medan berkordinasi dengan BPJS Kota Medan untuk menerima yang bersangkutan sebagai peserta PBI, Pemerintah dalam rangka perlindungan hukum bagi peserta PBI yang dinonaktifkan, pada konteks ini tentunya penting dengan menggunakan upaya perlindungan secara preventif yang dengan tujaun untuk mencegah terjadinya pelanggaran dengan terlebih dahulu melakukan sosialisasi ataupun pendataan ulang setiap tahunnya untuk memastikan 
kelayakan peserta PBI sebagai penerima bantuan iuran. Pendataan ulang tersebut juga untuk memastikan masyarakat masuk dalam daftar data terpadu kesejahteraan sosial sebagai acuan Dinas Sosial Kota Medan dalam hal merekomendasi PBI nonaktif kepada BPJS Kesehatan Kota Medan agar memperoleh pelayanan jaminan kesehatan.

\section{Pelaksanaan Jaminan Kesehatan Bagi Masyarakat Miskin di Kota Medan}

Pemerintah melalui Badan Penyelenggara Jaminan Sosial Kota Medan berwenang atas pelaksanaan jaminan kesehatan terhadap masyarakat miskin dalam hal memberikan data kepada rumah sakit ataupun puskesmas yang selanjutnya pembiayaan yang timbul dari pasien miskin tersebut ditanggung oleh BPJS selaku penyelenggara kesehatan.

Gambar 1. Skema Alur Pelaksanaan Pelayanan Kesehatan

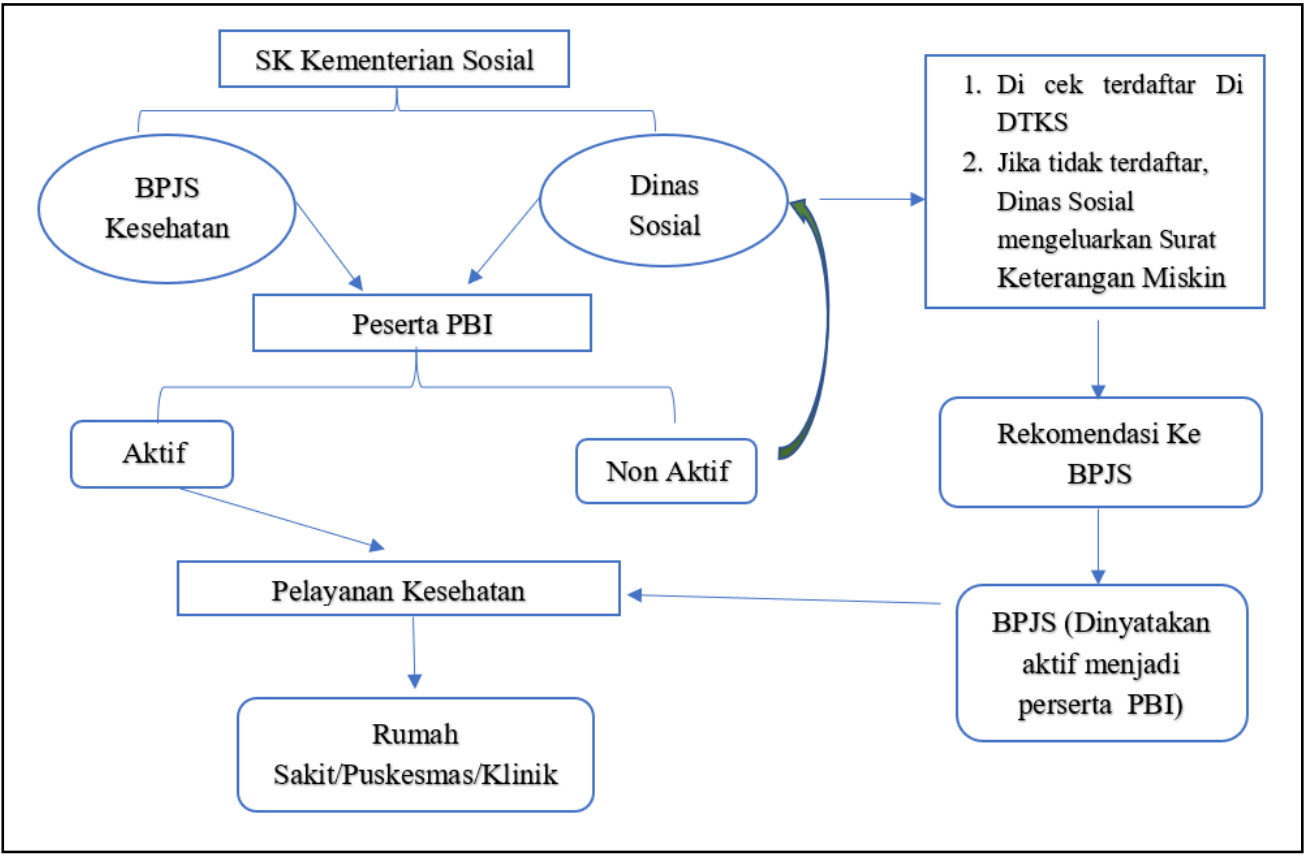

Sumber: Hasil wawancara oleh Bapak Arianto jabatan kepala seksi jaminan sosial keluarga dinas sosial Kota Medan

Sejauh ini penelitian yang dilaksanakan kepada BPJS Kota Medan untuk mengetahui kebijakan BPJS ataupun proses penyelenggara jaminan kesehatan bagi masyarakat miskin terkait SK Menteri Sosial No 79 Tahun 2019 tentang penonaktifan dan Perubahan Data Peserta Penerima Bantuan Iuran Jaminan Kesehatan Tahun 2019 Tahap ke enam, bahwa BPJS 
melaksanakan sosialisai secara masif untuk memastikan peserta PBI yang dinonaktifkan mengetahui informasi tersebut dan memahami apa yang harus dilakukan. Selanjutnya peserta PBI yang dinonaktifkan namun masih memenuhi syarat, peserta dapat jaminan kembali dengan mendaftarkan diri dan keluarganya ke dinas sosial atau dinas kesehatan setempat agar menjadi PBI APBD yang iuranya dijamin Pemerintah Daerah (Maaruf, 2019:32). Kemudian itu BPJS Kesehatan Kota Medan menerima data yang berhak untuk mendapatkan bantuan iuran kesehatan bagi masyarakat miskin berdasarkan data yang diserahkan oleh Dinas Sosial kota Medan.

\section{Penutup}

\section{A. Kesimpulan}

Perubahan data Peserta PBI menjadi non PBI dengan berdasarkan SK Menteri Sosial No. 79 Tahun 2019 tentang Penonaktifan dan Perubahan Data Peserta PBI Jaminan Kesehatan Tahun 2019 (Tahap ke Enam), sebagai penyesuaian anggaran belanja baik APBN atau APBD Propinsi dan kabupaten/kota. Perubahan tersebut terjadi dari dana APBN maupun APBD dan mengacu pada data terpadu kesejahteraan dengan perlu didukung semua pihak terkait dimana penyempurnaan DTKS dapat dilakukan. Perubahan pasien PBI menjadi Non PBI merupakan kebijkan kementerian sosial yang dimana Pemerintah melakukan pembaharuan data peserta PBI JK secara bertahap. Pendataan menjadi peserta PBI dilaksanakan oleh Dinas Sosial Kota Medan dengan melakukan pendataan yang dibantu oleh kepling/kepala daerah setempat. Pendataan dilakukan berdasrkan SK Menteri Sosial Republik Indonesia Nomor: 146/HUK/2013 tentang Penetapan Kriteria dan Pendataan Fakir Miskin dan Orang Tidak Mampu.

Perlindungan hukum terhadap masyarakat miskin akibat dari nonaktifnya kepesertaan PBI adalah kewajiban pemerintah melalui Dinas Sosial Kota Medan, tentunya pemerintah mampu memberikan hak masyarakat miskin dalam memperoleh jaminan pelayanan kesehatan. Dalam memberikan perlindungan dimana BPJS-Kesehatan Kota Medan dengan Dinas Sosial Kota Medan 
berkoordinasi satu sama lain dengan adanya pelaporan dari peserta PBI yang dinonaktifkan. Dalam hal ini pihak BPJS menuntun peserta PBI yang dinonaktifkan untuk melaporkan ke Dinas Sosial Kota Medan sehingga Dinas sosial akan menindaklanjuti dengan pengecekan data. Apabila pasien tidak terdata maka dikeluarkan surat keterangan miskin (SKM) oleh Dinas Sosial. Upaya perlindungan hukum yang diberikan merupakan perlindungan secara preventif yang dengan tujuan untuk mencegah terjadinya pelanggaran dengan terlebih dahulu melakukan sosialisasi ataupun pendataan ulang setiap tahunnya untuk memastikan kelayakan peserta PBI sebagai penerima bantuan iuran. Pendataan ulang tersebut juga untuk memastikan masyarakat masuk dalam daftar data terpadu kesejahteraan sosial sebagai acuan Dinas Sosial Kota Medan dalam hal merekomendasi PBI nonaktif kepada BPJS-Kesehatan Kota Medan agar memperoleh pelayanan jaminan kesehatan. Perlindungan hukum mangacu pada perpu yang mengatur hak akan jaminan atas kesehatan bagi kelompok fakir miskin dan tidak mampu melalui Pasal 1 angka 7, Pasal 18 ayat (1) dan Pasal 19 ayat (4) Undang-undang No. 24 Tahun 2011 tentang BPJS-Kesehatan yang menegaskan tanggungjawab pemerintah sebagai pemegang tanggungjawab dari hak atas jaminan kesehatan untuk menjamin bantuan iuran kepada peserta PBI jaminan kesehatan dan UU No.36 Tahun 2009 Tentang Kesehatan Pasal 4 ayat 1 dan Pasal 6 ayat 1 serta Pasal 4 UU No. 8 Tahun 1999 tentang Perlindungan konsumen.

\section{B. Saran}

Perlu dilaksanakan sosialisasi oleh dinas sosial kota medan yang dibantu oleh Kepala Desa/ Kepling tentang keluarnya surat keputusan kementerian sosial tentang perubahan data dan penonaktifan peserta PBI menjadi Non PBI.

\section{Daftar Pustaka}

Ari, F. (2012). Pengantar Kesejahteraan Sosial. Bandung: Refika Aditama.

Lestari, A. B. (2018). Panduan Layanan bagi Peserta Jaminan Kesehatan Nasoinal Kartu Indonesia Sehat (JKN-KIS). Jakarta: BPJS. 
Maaruf, M. I. A. (2019). Siaran BPJS Kesehatan, Kepala Humas BPJS Kesehatan. Jakarta: Siaran Pers.

Muchsin. (2003). Perlindungan dan Kepastian Hukum bagi Investor di. Indonesia. Universitas Sebelas Maret, Surakarta.

Pertiwi, A. (2016). Analisis Perbedaan Kualitas Pelayanan Pada Pasien BPJS dan Pasien Umum terhadap Kepuasan Pasien di Rawat jalan RSUD Kota Surakarta. Jurnal Manajemen Dayasaing, 18(2). https://doi.org/10.23917/dayasaing.v18i2.4508

Pertiwi, M., \& Nurcahyanto, H. (2017). Efektivitas Program BPJS Kesehatan di Kota Semarang (Studi Kasus Pada Pasien pengguna jasa BPJS Kesehatan di Puskesmas Srondol). Jurnal of Publik Policy and Manajemen Review, 6(2). https://doi.org/10.14710/jppmr.v6i2.16050

Putri, P. M., \& Murdi, P. B. (2019). Pelayanan Kesehatan di Era Jaminan Kesehatan Nasional sebagai Program Badan Penyelenggara Jaminan Sosial. Jurnal Wacana Hukum, 25(1). https://doi.org/10.33061/ 1.jwh.2019.25.1.3046

Republik Indonesia. Keputusan Menteri Sosial Republik Indonesia Nomor: 146/HUK/2013 tentang Penetapan Kriteria dan Pendataan Fakir Miskin dan Orang Tidak Mampu.

Republik Indonesia. Surat Keputusan Kementrian Sosial Republik Indonesia No. 76 Tahun 2019 Tentang Penonaktifan Dan Perubahan Data Peserta PBI Jaminan Kesehatan Tahun 2019.

Republik Indonesia. Undang-Undang No. 24 Tahun 2011 Tentang Badan Penyelenggara Jaminan Sosial.

Republik Indonesia. Undang-Undang Nomor 8 Tahun 1999 tentang Perlindungan Konsumen.

Sadi, M. (2017). Etika Hukum Kesehatan: Teori dan Aplikasinya. Jakarta: Prenada Media Group.

Sulastamo. (2011). Sistem Jaminan Sosial Nasional: Mewujudkan Amanat Konstitusi. Jakarta: Penerbit Buku Kompas.

Zaeni, A. (2017). Aspek-Aspek Hukum Jaminan Sosial Tenaga Kerja di Indonesia. Jakarta: Rajagrafindo Persada. 